\title{
LA CUESTIÓN MEDIOAMBIENTAL EN EL DIÁLOGO ECUMÉNICO
}

Fecha de recepción: 14 de enero de 2020

Fecha de aceptación: 02 de marzo de 2020

RESUMEN: Desde la preocupación inicial por los desafíos que planteaba el mundo tecnológico, pasando por la defensa de la sostenibilidad o la afirmación de la necesidad de desarrollar una ética medioambiental, hasta la cristalización de la tríada «Justicia, Paz e Integridad de la creación», el movimiento ecuménico ha prestado una atención creciente a la cuestión medioambiental, que ha pasado a convertirse en una dimensión nuclear de la visión de la oikumene para el siglo XXI. El ámbito ecuménico se ha revelado como un espacio de encuentro y convergencia entre unas Iglesias convencidas de que la crisis medioambiental es, además de una cuestión científica, un problema religioso y moral, y conscientes de que la problemática ecológica reclama una respuesta conjunta de parte de la fe cristiana.

PALABRAS CLAVE: ecología; ecumenismo; medioambiente; Consejo Ecuménico de Iglesias; «justicia, paz e integridad de la creación»; sostenibilidad; ética medioambiental.

\section{The Environmental Issue in the Ecumenical Dialogue}

ABSTRACT: The ecumenical movement has given increasing attention to the environmental issue, which has become a nuclear dimension of the vision of the oikumene in the $21^{\text {st }}$ century. The ecumenical field has revealed itself as a suitable space for

\footnotetext{
"Universidad Pontificia Comillas: cmbeunza@comillas.edu;

ORCID: https://orcid.org/0000-0002-9830-2204
} 
meeting and convergence between Christian Churches. In addition to a scientific question, the environamental crisis is a religious and moral issue. The ecological problem demands a joint response from the Christian faith. This article explores the increasing importance of this issue, from the initial concern for the challenges of a technological world to the proclamation of the work on «Justice, Peace and Integrity of Creation» as a crucial topic in the ecumenical agenda.

KEY WORDS: ecology; ecumenism; environment; World Council of Churches; «Justice, Peace and Integrity of Creation»; sustainability.

\section{LA CUESTIÓN MEDIOAMBIENTAL COMO ESPACIO DE CONVERGENCIA ECUMÉNICA}

En el verano de 1996 tuvo lugar en la ciudad austriaca de Graz la Segunda Asamblea Ecuménica Europea. Habían transcurrido solo siete años desde aquella primera asamblea celebrada en Basilea, que había situado la cuestión medioambiental en un primer plano de la agenda ecuménica europea. Pero, en ese tiempo, el continente había experimentado grandes cambios: la caída del muro de Berlín con el consiguiente derrumbamiento de los regímenes comunistas, las grandes expectativas que se habían abierto ante los progresos en el camino hacia una unidad europea que se habían visto truncadas por la emergencia de resentimientos raciales y nacionalismos de nuevo cuño, y la oscura sombra del conflicto de los Balcanes que había vuelto a teñir de sangre el suelo europeo. Europa - constataban los más de diez mil participantes en la asamblea- estaba necesitada de reconciliación: reconciliación con Dios, reconciliación entre pueblos y etnias, reconciliación entre unas Iglesias que reconocían haber presentado al mundo el espectáculo indigno de una cristiandad desgarrada por las divisiones, y reconciliación también con la naturaleza, con esa tierra que es nuestra casa, valiosa y vulnerable a la vez, que debía ser preservada para las futuras generaciones:

«Somos la primera generación de la larga historia de la humanidad que ha podido contemplar el planeta desde el exterior. Nos referimos a la tierra con el calificativo de "planeta azul", envuelto en capas de aire y gases, aparentemente perdido en la enorme extensión del universo [...] En contra de la concepción histórica de la tierra como un "mundo sin fin", ahora comenzamos a saber que es un planeta pequeño, finito y vulnerable. Esta idea, hoy superada, sobre la tierra nos dio la libertad de explotar los recursos naturales sin considerar su valor intrínseco 
y sin respetar sus límites. Es ahora cuando nos damos cuenta de que hemos sobrepasado los límites de su conservación y también que hemos asolado el hogar de los seres vivos, que es también el nuestro» ${ }^{1}$.

La asamblea invitaba a las Iglesias a realizar un nuevo ejercicio de responsabilidad ecológica. Les recomendaba que promovieran la «salvaguardia de la creación» como una dimensión esencial de la vida eclesial y les animaba a impulsar iniciativas que incidieran en el ámbito político. Había llegado el momento de pasar a la acción. Los delegados reunidos en Graz expresaban otra firme convicción: «Las Iglesias cristianas necesitan el diálogo ecuménico para redescubrir y revivir en las diversas tradiciones cristianas aquellos elementos nuevos que nos ayuden a comprender y cumplir mejor nuestra responsabilidad con la creación de Dios»².

En realidad, las Iglesias llevaban ya varias décadas dialogando sobre una cuestión que, como había recordado en Basilea el entonces secretario del Consejo Ecuménico de Iglesias (CEI), Emilio Castro, «concierne a la vida interior de las Iglesias y de los cristianos, a la credibilidad de su testimonio, a la eficacia de su compromiso y de su servicio» ${ }^{3}$. Lo habían hecho desde un doble presupuesto: impulsados por el convencimiento de que, en un mundo globalizado e interdependiente, los problemas a los que se enfrenta la humanidad reclaman una respuesta ecuménica conjunta por parte de las Iglesias; y desde la convicción, tan evidente como en ocasiones discutida en el ámbito ecuménico, de que el compromiso por la justicia y la vida es parte integral de la vocación ecuménica. Dicho compromiso ha cristalizado en lo que ha venido en denominarse "pensamiento social ecuménico», del que forma parte la cuestión medioambiental, que en las últimas décadas ha quedado condensado en la triada «justicia, paz e integridad de la creación», expresión que ha adquirido carta de ciudadanía en los ámbitos ecuménico e interreligioso y que, en

${ }^{1}$ Conferencia de Iglesias Europeas (KEK) - Consejo de las Conferencias Episcopales de Europa (CEE). Reconciliación: don de Dios y fuente de nueva vida (Segunda Asamblea Ecuménica Europea. Graz 1997). Madrid: PPC, 1997, 34.

2 Ibid., 82.

3 Conferencia de Iglesias Europeas (KEK) - Consejo de las Conferencias Episcopales de Europa (CEE). Paz con Justicia. Documentación oficial de la Asamblea Ecuménica Europea. Basilea, 15-21 mayo 1989. Madrid: Centro Ecuménico Misioneras de la Unidad, 1990, 85. 
la línea de la encíclica Laudato si', vincula estrechamente justicia social y ecología ${ }^{4}$.

Ese pensamiento social ecuménico, que constituye el marco en el que se aborda la problemática ecológica, tiene su origen en la organización denominada Vida y Acción, surgida en 1925 del impulso del arzobispo luterano de Upsala Nathan Söderblom. Söderblom abanderaba aquella corriente del naciente movimiento ecuménico que, dejando de lado los planteamientos teológicos, había decidido concentrarse en lo que se definían como cuestiones «de orden práctico». Su filosofía quedó pronto condensada en el lema «la doctrina separa, la acción une». En sus filas se aglutinaban aquellos pioneros de la causa ecuménica que buscaban responder con un testimonio común a los problemas de la sociedad.

Aunque Vida y Acción había nacido fuertemente influenciada por aquella fe en el progreso que teñía los mejores proyectos de la teología liberal, el incuestionable optimismo en las posibilidades de la civilización científico-técnica que caracterizó al movimiento ecuménico en sus primeras décadas no iba a tardar en verse matizado. La evolución del tratamiento de la problemática medioambiental en el ámbito ecuménico es precisamente uno de los ámbitos donde se percibe con mayor claridad algo que ha señalado el teólogo R. Gibellini: el cambio de perspectiva que ha promovido la problemática ecológica en la confrontación entre el cristianismo y la modernidad ${ }^{5}$. La constatación de que la destrucción del entorno natural está conectada con la relación de dominio de la naturaleza que surgió como una dimensión de la civilización moderna, ha obligado al cristianismo a hacer una valoración más crítica y matizada de esa modernidad científica y tecnológica que, junto a enormes beneficios para la humanidad, ha impulsado igualmente una actitud de arrogancia que ha puesto en riesgo la supervivencia del planeta.

En el año 1968, el historiador norteamericano Lynn White situó en el punto de mira a la fe cristiana, atribuyendo al cristianismo una especial

${ }^{4}$ El papa Francisco ha subrayado la relación que media entre la ecología y la justicia social en los siguientes términos: «Hoy no podemos dejar de reconocer que un verdadero planteo ecológico se convierte siempre en un planteo social, que debe integrar la justicia en las discusiones sobre el ambiente, para escuchar tanto el clamor de la tierra como el clamor de los pobres» (LS 49).

5 Cf. Rosino Gibellini. "El debate teológico sobre la ecología". Concilium 261 (1995): 901-912. 
responsabilidad en la actual crisis medioambiental ${ }^{6}$. Desde entonces, como reconoce $\mathrm{Ch}$. Uehlinger, «con mayor o menor justificación, la doctrina del dominium terrae ha pesado como grave hipoteca sobre la teología y la antropología cristianas acerca de la creación» ${ }^{7}$. W. Pannenberg había formulado el pliego de descargo, mostrando que «la antropología bíblico-cristiana, correctamente desarrollada, se encuentra mejor capacitada para enfrentarse con la crisis ecológica que la autonomía absoluta de la cultura de la modernidad ${ }^{8}$. Algo que, por otro lado, parecía intuir ya el propio White quien, en el mencionado artículo, sostenía que «más ciencia y tecnología no va a sacarnos de la presente crisis ecológica a menos que encontremos una nueva religión o repensemos la nuestra ${ }^{9}$. Desde la convicción de que la crisis medioambiental entraña una dimensión ética y espiritual que no puede soslayarse, las Iglesias han tratado de contribuir al desarrollo de un ethos ecológico:

«Al igual que en todos los desafíos contemporáneos, estamos convencidos de que no puede abordarse y resolverse el problema ecológico sin la implicación y la contribución de las religiones, las antiguas y poderosas fuerzas del espíritu, que se centran en alimentar y desarrollar el núcleo del ser humano. La promoción de la protección del entorno natural ocupa un lugar central en el diálogo de las religiones y en la colaboración interreligiosa. Las religiones y las Iglesias pueden hacer una contribución importante al desarrollo de un ethos ecológico» ${ }^{10}$.

Esa reflexión se ha desarrollado, en gran medida, en el ámbito ecuménico. Se puede, en ese sentido, afirmar que el despertar de las Iglesias a la ecología ha sido un despertar ecuménico. A diferencia de lo que ha sucedido con otras cuestiones de carácter ético, que en las últimas décadas han suscitado fuertes controversias entre las Iglesias, la cuestión medioambiental se ha revelado como un espacio de convergencia y cooperación ecuménica, que se ha visto reflejada en documentos, declaraciones e iniciativas conjuntas, en las que el mundo ortodoxo ha cobrado un especial protagonismo. En las páginas que siguen realizaremos un

${ }^{6}$ Cf. Lynn White. "The Historical Rootes of Our Ecological Crisis”. Science 155 (1967): 1203-1207.

7 Christoph Uehlinger. "El clamor de la tierra, el clamor de los pobre. Perspectivas bíblicas sobre el tema 'ecología y violencia”’. Concilium 261 (1995): 808.

8 Gibellini, 902.

9 White, 1206.

10 Bartolomé I. “Eclesiología como ecología”. Concilium 378 (2018): 625. 
recorrido que muestre cómo ha ido emergiendo la cuestión medioambiental en el ámbito ecuménico, hasta configurarse como una cuestión nuclear de la reflexión y acción conjunta de las Iglesias.

\section{EL CAMINO HACIA UNA «SOCIEDAD RESPONSABLE»: LOS AN- TECEDENTES DE LA CUESTIÓN MEDIOAMBIENTAL}

La prehistoria de lo que hoy denominamos la cuestión medioambiental se deja rastrear en el marco de la institución fundada por Söderblom que, ya en su segunda conferencia celebrada en Oxford en 1937, se vio forzada a abordar la teología de la creación, núcleo gordiano de la problemática ecológica ${ }^{11}$. La conferencia se reunía con el trasfondo de la profunda crisis política, social y teológica que atravesaba la Europa de entreguerras. El naciente movimiento ecuménico se enfrentaba a una acuciante pregunta: ¿cómo reaccionar ante el peligro de ideologización de la fe cristiana puesta al servicio del programa político del nacionalsocialismo alemán? El proyecto histórico del nacional-luteranismo y su intento de buscar una justificación del régimen nazi en la teología de los «órdenes de la creación», justificaba la superioridad de la raza aria interpretada como expresión del proyecto creador de Dios.

Bajo un fuerte influjo del pensamiento barthiano, el movimiento ecuménico se adhirió en Oxford a la crítica de la teología dialéctica. Denunció la tentación de considerar los valores de un pueblo o del estado como expresión clara e inmediata de la voluntad de Dios, recuperando la distinción entre la revelación de Dios en Cristo y las estructuras terrenas del mundo. La conferencia mostró su firme oposición a cualquier tentativa de buscar la palabra de Dios en los acontecimientos históricos, en el pueblo, en la raza, o en unos «órdenes de la creación» desvinculados de la persona de Cristo. Se enfrentó a la confusión de la historia profana con la misma historia de la salvación y alertó de uno de los errores de esta teología: su deficiente articulación entre creación y redención, que entrañaba el riesgo de separar los «órdenes de la creación» del resto de la revelación, dando lugar a una identificación de las leyes de la nación con la ley de Dios manifestada en los órdenes de la creación. El movimiento ecuménico había respondido al desafío lanzado por D. Bonhoeffer, mostrándose

${ }^{11}$ Cf. John H. Oldham, ed. The Oxford Conference (Official Report). Chicago: 1937. 
como un movimiento confesante capaz de hablar un lenguaje profético, consciente de que la identidad de la Iglesia se jugaba en su interacción con el mundo. Pero, como afirmaría décadas más tarde J. Moltmann, aquel episodio tuvo una importante consecuencia, bloqueando durante años el desarrollo y profundización de la teología de la creación y de la historia, núcleo gordiano de la problemática ecológica:

«La doctrina de la creación —escribe Moltmann en 1985- no ha constituido un tema específico de la teología evangélica alemana - y tampoco del movimiento ecuménico, podríamos añadir- desde las discusiones que la "Iglesia Confesante" y los "Cristianos alemanes" protagonizaron en los años de la dictadura alemana. Impresionaba demasiado la alternativa de entonces: o "teología natural", que cree poder conocer el orden divino partiendo de los datos del pueblo, raza y voluntad de Dios en la historia de la toma del poder por Hitler, o "teología de la revelación", que considera a Jesucristo como "la palabra única de Dios", como afirmaba en su primera tesis la Declaración teológica de Barmen, de 1934. Los problemas que Karl Barth, Emil Brunner, Friedrich Gogarten y Paul Althaus trataron entonces en el contexto de la teología europea siguen teniendo plena vigencia y no han sido superados» $»^{12}$.

Como ha recordado L. Vischer, el tema de la creación se incorporó tarde al debate ecuménico. El teólogo reformado señalaba como una de las razones principales la tendencia a separar las esferas de la naturaleza y de la historia dejando, no solo la investigación de la naturaleza, sino también su interpretación a la ciencia ${ }^{13}$.

12 Jürgen Moltmann. Dios en la creación. Salamanca: Sígueme, 1987, 9. Sobre este particular, véase: Héctor Vall. La búsqueda de una nueva sociedad (Dimensión social del ecumenismo). Madrid: Sociedad de Educación Atenas - Centro Ecuménico «Misioneras de la Unidad», 1997, 64-68. 83-84. Vall se refiere a la experiencia de los «cristianos alemanes» y su utilización de la teología de los "órdenes de la creación» como causa principal de la ausencia de una teología de la creación en las décadas posteriores.

13 Lukas Vischer. "The Theme of Humanity and Creation in the Ecumenical Movement". En Sustainable Growth - A Contradiction in Terms? Economy, Ecology and Ethics Afther the Earth Summit, Report of the Visser't Hooft Memorial Consultation, The Ecumenical Institute, Château de Bossey, June 14-19, 1993, 69. Geneva: World Council of Churches, 1993. R. Gibellini lo explica del siguiente modo: «En el ámbito cristiano se ha pactado tácitamente una especie de reparto de competencias: la naturaleza ha sido abandonada a la ciencia y a la tecnología, mientras que la teología se 
El fin de la Segunda Guerra Mundial inaugura una realidad totalmente diferente. La fundación del Consejo Ecuménico de Iglesias en 1948, estrechamente vinculada a los esfuerzos por crear un nuevo orden internacional, supone un paso adelante en la reflexión sobre los grandes problemas de la humanidad. En su asamblea inaugural, convocada bajo el lema «Desorden de los hombres y designio de Dios», se apuntaba ya a la cuestión tecnológica como uno de los ámbitos llamado a reclamar el foco de atención en las décadas siguientes:

«Con frecuencia - las Iglesias- no han visto más que el lado puramente espiritual, escatológico o individual de su mensaje y de su responsabilidad. Incapaces de comprender las fuerzas que, a su alrededor, dan forma a la sociedad, no se han hallado dispuestas en el momento oportuno a dar soluciones positivas a los problemas nacidos de la civilización técnica» ${ }^{14}$.

La Asamblea acuña el concepto «sociedad responsable», formulado como un intento de establecer criterios sociales y éticos, que sirvieran como referentes y criterios para evaluar críticamente el comunismo y el capitalismo.

\section{EL HOMBRE Y LA REVOLUCIÓN TECNOLÓGICA: LOS INICIOS DEL DEBATE MEDIOAMBIENTAL}

En el contexto postbélico — caracterizado por rápidos cambios sociales, por ideologías en conflicto, revoluciones nacionales y raciales, movimientos de liberación social y por una creciente diversidad cultural—, va a emerger una problemática nueva que puede enmarcarse bajo el epígrafe «el hombre y el desarrollo tecnológico», que dominará el pensamiento social ecuménico en las décadas de 1960 y 1970, y que va a pasar de una preocupación por las consecuencias que ese desarrollo tiene para la humanidad a un interés creciente por las implicaciones medioambientales de la tecnología. Como ha mostrado el ecumenista H. Vall, en las reuniones

reservaba la historia, interpretada como historia de la salvación. Pero de ese modo la teología no ha hecho culturalmente operante la fe en la creación». Gibellini, 904.

${ }^{14}$ Citado en: Vall, 84. 
y asambleas del CEI y de los organismos ecuménicos se observa una progresiva maduración de los temas ecológicos ${ }^{15}$.

Esta etapa va a quedar enmarcada por las Asambleas del CEI de Upsala (1968) y Nairobi (1975) y dos grandes conferencias: la celebrada en 1966 en Ginebra por el departamento Iglesia y Sociedad del CEI con el tema «Los cristianos en las revoluciones técnicas y sociales de nuestro tiempo»; y la conferencia organizada por el CEI en el Massachusetts Institute of Technology (MIT) en 1979 con el título «La contribución de la fe cristiana, la ciencia y la tecnología en la lucha por una sociedad justa y sostenible» que, con la participación de más de 400 científicos, marcará la apertura a un diálogo entre teólogos y científicos. Junto a la labor desarrollada por el departamento Iglesia y Sociedad, será determinante la reflexión teológica elaborada por la Comisión Fe y Constitución del CEI. Una de las características más relevantes de este periodo es que el pensamiento social ecuménico recupera como tema teológico la presencia y la acción de Dios en la historia de los hombres y en la misma naturaleza ${ }^{16}$.

\subsection{La teOlogía de La CREACión EN LA AGENDA ECUMÉNica}

La intervención del teólogo norteamericano Joseph Sittler en la asamblea de Nueva Delhi (1961) del CEI introducía en la agenda ecuménica la cuestión medioambiental. Su alocución — que partía del himno de Col 1,15-20 - desarrollaba una cristología cósmica, planteando el tema de la salvación de toda la creación. La intervención quedaba condensada en el siguiente axioma: «la doctrina de la redención es significativa en la medida en que se sitúa en el marco de la doctrina de la creación ${ }^{17}$. El mundo creado por Dios - argumentaba Sittler - no puede ser redimido de un modo inteligible si es separado de la doctrina del cosmos que es su hogar. Todas las cosas son permeables a la redención cósmica, porque todo subsiste en Él. La redención en Cristo no solo concierne al individuo, incluye a la naturaleza y a la creación entera. La suya era una invitación a superar toda interpretación dualista que, separando naturaleza y gracia, reconoce la presencia de Dios en la interioridad del hombre pero no en

15 Cf. Ibid., 84-122.

${ }^{16}$ Cf. Ibid., 64.

17 Joseph A. Sittler. "Called to Unity". The Ecumenical Review XIV, n. 2 (1962): 177-187. DOI: https://doi.org/10.1111/j.1758-6623.1962.tb01999.x. La cita en p. 178. 
la naturaleza o en la historia ${ }^{18}$. «Naturaleza y gracia —afirma- son ambas categorías necesarias para hacer justicia al Dios salvador del mundo. Considerarlas como categorías absolutas contradictorias distorsiona y minimiza la doctrina de la creación ${ }^{19}$. Su alocución dejaba trazada la trayectoria futura: «El camino a seguir pasa por una cristología ampliada en sus dimensiones cósmicas, apasionada por el pathos de una tierra amenazada y éticamente comprometida con el amor y la cólera divinos $»^{20}$.

La sugerencia de Sittler fue recogida por la Comisión Fe y Constitución, que se preguntó en qué medida la relación entre creación y redención formaba parte de la reflexión sobre la unidad de la Iglesia. La reflexión, que se prolongó durante tres años (1964-1967) cristalizó en el documento "Dios en la naturaleza y en la historia»" ${ }^{21}$. Considerado por L. Vischer como uno de los textos más notables de Fe y Constitución ${ }^{22}$, el documento se asienta sobre un claro presupuesto: que el Dios revelado en Cristo es, al mismo tiempo, el Dios de la creación y el Dios de la historia. La historia y la naturaleza están, por tanto, gobernadas por una misma voluntad salvadora. El texto establece una conexión cristológica entre la creación y la redención.

La reflexión comienza con una constatación: «Sin haberlo buscado deliberadamente, el hombre moderno se ha visto confrontado con una experiencia y una compresión nuevas de la naturaleza y de la historia ${ }^{23}$. La concepción estática de la naturaleza y de la historia que había prevalecido durante siglos ha quedado superada, dando paso a una visión modelada por las teorías evolucionistas: «la naturaleza ha dejado de ser una entidad estática, geocéntrica y limitada, para configurarse como una

18 Sittler apoyaba su argumentación en la siguiente afirmación del teólogo Allan D. Galloway: «A menos que se esté dispuesto a aceptar un dualismo que condena el mundo físico como algo que no proviene de Dios y se interprete la redención únicamente como una liberación del orden físico, es preciso afrontar la cuestión de la redención cósmica, no en contraste sino como una implicación de la redención personal». Ibid., 178-179.

19 Ibid., 180.

20 Ibid., 168.

${ }^{21}$ Faith and Order Commission. "God in Nature and History". En New Directions in Faith and Order, Bristol 1967. Reports, Minutes, Documents. Geneva: World Council of Churches, 1968, 7-32. El documento fue probado en la reunión de Bristol (1967) y presentado en la Asamblea de Upsala (1968) del CEI.

22 Cf. Vischer, 70.

${ }^{23}$ Faith and Order Commission, 7. 
entidad en evolución en un espacio indeterminado y en un tiempo casi ilimitado ${ }^{24}$. Es necesario preguntarse por el sentido teológico de ese proceso histórico de cambio, que implica ver la realidad de un modo dinámico. Es igualmente necesario, afirmaba el texto, «presentar una nueva comprensión de lo que el Antiguo y el Nuevo Testamento enseñan sobre la presencia activa de Dios en la naturaleza y en la historia» ${ }^{25}$. El estudio significa un primer intento de establecer en el ámbito ecuménico un diálogo con la ciencia moderna de la naturaleza y su cosmovisión. Trata de mostrar una compatibilidad entre la teoría científica de la evolución y la comprensión bíblica de la naturaleza como creación de Dios que, sin implicar la identificación de la fe cristiana con la cosmovisión moderna, supere lo que considera una falsa alternativa que obligaría a elegir entre una concepción cristiana estática de la creación y de la historia y la idea moderna de evolución.

El texto anticipaba una respuesta a la crítica abanderada por L. White, que convertía al cristianismo en máximo responsable de una crisis ecológica que mostraba ya signos visibles, estableciendo los parámetros de una correcta relación entre el hombre y la naturaleza:

«El hombre vive en una triple relación: como hijo de Dios, compañero de su prójimo y señor de la naturaleza. Cuando una de estas relaciones es distorsionada, las otras se ven afectadas. Cuando el hombre, señor de la naturaleza, renuncia a poner su señorío al servicio de Dios y de su prójimo, niega el verdadero propósito de su dominio, dañando a la naturaleza; del mismo modo, cuando el hombre no se siente protegido por la presencia paterna de Dios, la naturaleza se transforma en una amenaza y un adversario ${ }^{26}$.

\subsection{Los DESAFíos DEL MUNDO TECNOLÓGICO}

La conferencia organizada en 1966 por el departamento Iglesia y Sociedad se preguntaba de nuevo cómo podían los cristianos discernir la acción de Dios en la historia. Pero en esta ocasión lo que estaba en el punto de mira era el problema de la tecnología y su importancia para la vida humana. El mundo ecuménico se había hecho consciente del gran

\footnotetext{
${ }^{24}$ Ibid., 7.

25 Ibid., 8.

26 Ibid., 20.
} 
reto que implicaba la nueva revolución científica y técnica: «El hombre moderno - constataba uno de los informes- se halla frente a la tecnología como ante un hecho esencialmente nuevo en toda la historia» ${ }^{27}$. Si la Conferencia de Oxford había mostrado que las cuestiones políticas y sociales tenían implicaciones religiosas y, por ello mismo, reclamaban un tratamiento teológico, ahora era el desarrollo tecnológico el que suscita nuevos interrogantes y reclamaba un análisis teológico y un compromiso ético:

«El hombre se halla en una nueva crisis histórica, que nace de la influencia cumulativa de la tecnología. La visión de conquista del cosmos le confiere un poder - un poder para el bien o para la destrucción-que nunca ha poseído antes. El uso o el abuso de ese poder es, fundamentalmente, un problema ético» ${ }^{28}$.

La convicción de que la fe cristiana entrañaba una responsabilidad en la transformación de la sociedad había sido formulada por el secretario general del CEI, W. Visser 't Hooft en su discurso de apertura:

«Por suerte el movimiento ecuménico ha descubierto una norma ética de acción creadora en el corazón de los problemas de nuestro mundo, a través de los debates sobre problemas sociales y por el desarrollo mismo que ha dado la noción "sociedad consciente de sus responsabilidades". Hoy es necesario renovar esta noción y reinterpretarla para responder a las necesidades de construir una comunidad mundial consciente de sus responsabilidades y de las exigencias de la justicia económica e internacional ${ }^{29}$.

En Ginebra se discutió ampliamente el problema de la tecnología y su importancia para la vida humana. Se constató cómo la tecnología estaba transformando las relaciones entre el hombre y la naturaleza. Este cambio que, por una parte, suscitaba la esperanza de las posibilidades de la aplicación de la revolución tecnológica a las necesidades del desarrollo,

27 Departamento Iglesia y Sociedad. Los cristianos en las revoluciones técnicas y sociales de nuestro tiempo. Documentos de la conferencia mundial sobre Iglesia y Sociedad (Ginebra, 12-26 julio 1966). Santander: Sal Terrae, 1971, 213. La conferencia se celebraba en el contexto de una profunda toma de conciencia de la crítica situación social que atravesaba la humanidad, marcada por la ambivalencia de la técnica moderna, el subdesarrollo del Tercer Mundo y la lucha por la justicia mundial.

28 Ibid., 216.

29 Citado en: Vall, 37-38. 
no dejaba sin embargo de despertar serios interrogantes. La tecnología mostraba su poder ambivalente, podía emplearse para construir y liberar, pero también para esclavizar y destruir: «a diferencia de nuestros antepasados, nosotros tenemos el poder de alimentar a todos los niños y de reducir nuestro planeta a cenizas, de erradicar muchas enfermedades dolorosas y desencadenar epidemias por medio de armas bacteriológicas ${ }^{30}$. Sin referirse todavía a los efectos medioambientales de la tecnología, sí quedaban planteados los serios efectos secundarios comunes a toda sociedad tecnológica: contaminación del aire y del agua, nuevas enfermedades profesionales, etc. Se advertía igualmente de algunos efectos más profundos, como la transformación de las relaciones entre el hombre y la naturaleza, el cambio radical de las formas de trabajo y de la organización económica o la alteración de las formas de asociación humana y de la estructura de la sociedad. Se constataba, en definitiva, la necesidad de prestar atención tanto a los efectos pretendidos como a los no deseados del desarrollo tecnológico:

«El punto de vista bíblico es que no hay necesidad de poner límites al poder del intelecto humano ni al empleo que él haga de la naturaleza. Pero si bien esas facultades humanas no parecen tener límites, el sentimiento que el hombre tiene de ser el administrador responsable de la creación de Dios es un sentimiento que debe ir creciendo de manera proporcional a la expansión de sus poderes; el hombre debe conservar los dones del mundo creado y utilizarlos respetuosamente, como parte que son del plan de toda la creación» ${ }^{31}$.

La conferencia entrañaba un esfuerzo por comprender las realidades revolucionarias que estaban modelando el mundo moderno y responder a ellas desde la fe cristiana. Se estaban produciendo cambios profundos y acelerados en sectores fundamentales de la vida humana. Se tenía conciencia de que la sociedad se encontraba en una nueva fase de su historia cultural, política y económica, motivada por las grandes transformaciones que se estaban sucediendo en el campo del desarrollo tecnológico, en las comunicaciones y en los ámbitos económico y político. Las enormes posibilidades y, al mismo tiempo, los nuevos problemas surgidos de ese desarrollo hacían urgente el establecimiento de nuevos sistemas de valores que integrasen el conjunto de ese crecimiento. Ante esta situación,

30 Departamento Iglesia y Sociedad, 274.

31 Ibid., 216. 
se mostraba una clara convicción: «la Iglesia tiene la responsabilidad de comprender y juzgar el impacto del cambio tecnológico a la luz de la voluntad de Dios acerca de la redención del hombre» ${ }^{32}$.

\subsection{El CAMINO HACIA UNA SOCIEDAD «JUSTA Y SOSTENIBLE»}

La creciente incorporación de Iglesias del Tercer Mundo se dejó sentir en la IV Asamblea del CEI (Upsala, 1968). Las realidades de los países en vías de desarrollo se hicieron fuertemente presentes en el transcurso de la misma: cuestiones como la pobreza, el subdesarrollo, el racismo o las desigualdades Norte-Sur pasaron a formar parte de la agenda ecuménica. La preocupación central de la asamblea se concentró en los graves problemas que afectaban a la sociedad, con sus injusticias e incertidumbres. En ese sentido, fue una profunda toma de conciencia de la trágica situación social de la humanidad, constatándose el mal uso de la técnica moderna, el subdesarrollo de todo el Tercer Mundo y la necesidad de luchar para obtener una justicia mundial. La sección titulada «el desarrollo económico y social del mundo» constataba cómo habían emergido dos factores nuevos, la revolución técnica y la exigencia de justicia social de los pueblos: «En realidad — declaraba el informe de dicha sección-, la acción recíproca entre la tecnología y la justicia social constituye uno de los problemas fundamentales de nuestra época» ${ }^{33}$.

Marcada por un fuerte acento antropológico, la preocupación por el hombre y sus problemas constituyó el núcleo de la asamblea, tal y como quedaba reflejado en el expresivo título del artículo publicado por José María Javierre: "Upsala 1968: el diálogo ecuménico bajo el signo de la antropología" ${ }^{34}$. La asamblea abordó las cuestiones que plantea la sociedad técnica para la antropología y la teología de la creación:

«Los descubrimientos científicos y los movimientos revolucionarios de nuestra época abren nuevas posibilidades y peligros para los hombres. El hombre está perdido, porque no sabe ya quién es. Pero Dios

32 Ibid., 213-214.

33 Consejo Ecuménico de Iglesias. Upsala 1968. Informes, declaraciones y alocuciones. Salamanca: Sígueme, 1969, 126.

34 José María Javierre. “Upsala 1968: el diálogo ecuménico bajo el signo de la antropología”. Revista Española de Teología 28 (1968): 255-296. 
hace nuevas todas las cosas. El mensaje bíblico responde a la pregunta acerca del hombre: el hombre es el administrador de Dios para toda la creación» ${ }^{35}$.

En uno de sus informes, expresaba la concepción bíblica del hombre en los siguientes términos:

«La meta de Dios para el hombre es convertirlo en hijo suyo responsable. Dios le entrega el dominio sobre el resto de la creación, para que el hombre sea —en el universo- su administrador. El hombre es algo así como un gozne entre Dios y el universo de la creación: el que ha de dar la respuesta a Dios. Y así, el hombre está llamado a una relación de administración responsable con respecto al ambiente que le rodea, a una relación de fraternidad responsable hacia todos los hombres» ${ }^{36}$.

La asamblea urgió al Departamento Iglesia y Sociedad a lanzar un nuevo programa de estudio sobre el tema «El futuro del hombre y de la sociedad en un mundo basado en la ciencia y la tecnología», que prestara una atención particular a los problemas del cambio tecnológico a escala mundial ${ }^{37}$. Tras la iniciativa se encontraba la constatación de que la humanidad se enfrentaba a una segunda revolución tecnológica, en la que estaban en juego los valores humanos básicos y la convicción de que el modo en que se empleara la tecnología sería determinante para el futuro. En la primera de las conferencias que desarrollaron dicho programa el secretario general del CEI, Eugene Carson Blake, señalaba tres aspectos que debían ser abordados: la naturaleza y meta de la revolución científica y tecnológica; sus consecuencias para el hombre y la sociedad; y la interpretación ética y teológica de su significado para el hombre y

35 Consejo Ecuménico de Iglesias. Upsala, 18.

36 Ibid., 56-57.

37 El programa se desarrolló en sucesivas conferencias: conferencia sobre «Tecnología y futuro del hombre y de la sociedad» (Ginebra 1970); conferencia de Iglesia y sociedad «El futuro del hombre y la sociedad en un mundo basado en la ciencia y en la tecnología» (1971), que contó con la presencia del economista británico E. F. Schumacher, que presentó su libro Small is beautiful y de Joergen Randers, coautor del primer informe del Club de Roma The Limits to Growth (los límites del crecimiento); conferencia de Bucarest (1974), «Ciencia y tecnología para el desarrollo humano. El futuro ambiguo y la esperanza cristiana», que introduce el concepto de «sostenibilidad»; y la conferencia de Boston (1979), que implicó un avance notable en la relación entre ciencia y fe. 
su destino en la tierra ${ }^{38}$. El contexto había cambiado significativamente. El optimismo ante las posibilidades de un poder tecnológico capaz de erradicar la miseria había dado paso a una creciente preocupación por la amenaza de una catástrofe ecológica, provocando lo que se denominaba el «shock del futuro»:

«La indiferencia optimista de años anteriores iba cediendo el puesto a una pérdida corporativa de los nervios, cuando los hombres comenzaron a vislumbrar la inmensidad de las exigencias que surgían de la necesidad de planear con responsabilidad el futuro del hombre y de la sociedad en un mundo de tecnología basada en la ciencia» ${ }^{39}$.

Tal y como reflejaban los estudios científicos, se empezaba a percibir la magnitud de la crisis ecológica. El mundo ecuménico parecía despertar de lo que ahora se revelaba como una fe excesivamente optimista y un tanto frívola en el progreso tecnológico. El Comité Central del CEI alertaba de ello:

«Muchos han comprendido de repente, con aterradora intensidad, que estamos llegando a los límites de un mundo finito, que con toda verosimilitud algo de vital importancia va a desaparecer muy pronto, y que las repercusiones traumáticas que sobre nosotros recaerán están llenas de posibilidades trágicas [...] La tecnología y la ciencia han ampliado enormemente el dominio del hombre sobre la tierra, pero no sólo han enriquecido la vida, sino que también, en contrapartida, han creado problemas de contaminación, de agotamiento de recursos, de subordinación del hombre a la máquina y sobre todo de injusticia. Hay naciones y grupos dentro de las naciones que se sirven de la técnica y de la ciencia para dominar y explotar a otras naciones y grupos, con lo que aumenta cada día más el abismo entre ricos y pobres ${ }^{40}$.

Por otro lado, se constataba que los viejos problemas hacia los que el capitalismo y el marxismo trataban de orientarse habían perdido gran parte de su significación, mientras habían surgido nuevos problemas para los que dichos sistemas carecían de respuestas adecuadas. Y se consideraba

${ }^{38}$ Cf. David M. Gill, ed. Tecnología, fe y futuro del hombre. Salamanca: Sígueme, 1972, 27.

39 Ibid., 20-21.

40 Citado en: Antonio Matabosch. Liberación humana y unión de las Iglesias. El Consejo Ecuménico entre Upsala y Nairobi (1968-1975). Ediciones Cristiandad: Madrid, 1975, 209-210. 
que las Iglesias se habían mostrado poco conscientes de la significación y de las graves implicaciones de la era científica y tecnológica. Les había faltado una verdadera comprensión de lo que entrañaba ese proceso de transformación. Por ello, la revolución tecnológica debía considerarse una de las prioridades más urgentes de la agenda ecuménica. Era necesario plantear con responsabilidad el futuro del hombre y de la sociedad en un mundo tecnológico basado en la ciencia. Se imponía igualmente la búsqueda de una comprensión verdaderamente ecuménica de la responsabilidad social, pues la tecnología estaba generando efectos diversos en el Primer y Tercer Mundo. En las sucesivas conferencias organizadas en el marco del nuevo programa impulsado por Iglesia y Sociedad, iban cristalizando algunas convicciones.

En primer lugar, se afirmaba la necesidad de plantear de modo nuevo la relación entre el hombre y la naturaleza. Esa nueva relación no podría ya venir ni de una consideración mecanicista de la ciencia ni de una filosofía materialista. Era necesario replantear el criterio cristiano sobre la actividad creadora de Dios en un mundo en que dominaba el punto de vista científico del reduccionismo y el materialismo ${ }^{41}$. La división entre naturaleza e historia debía ser superada, al tiempo que debía articularse una teología de la naturaleza en consonancia con la nueva sensibilidad ecológica ${ }^{42}$.

Los análisis habían dejado claro que el futuro del hombre y de la tierra como medio ambiente natural del hombre estaban indisolublemente ligados entre sí, y no podían ser estudiados por separado. El hombre y la tierra tenían una historia común. Ello obligaba a tener una visión holística. La estrecha conexión que media entre nuestra imagen de la naturaleza y el modo en que la manipulamos se había hecho patente. En ese sentido, la ideología de la naturaleza dominante en la cristiandad occidental había sido la misma que había dominado en el mundo secular: una consideración tecnocrática y egoísta que le asignaba un valor meramente instrumental. La teología tenía una misión que cumplir: debía redescubrir la unidad de toda la creación a la luz de la comprensión cristiana del hombre. Las Iglesias podían aportar una visión alternativa: una visión

41 Cf. Vall, 108.

${ }^{42}$ André Dumas lo expresaba en los siguientes términos: «Estamos en un momento decisivo, en que la naturaleza recupera su legitimidad junto a la historia». Citado en: Matabosch, 218. 
«sacramental», que acentuase el valor intrínseco de cada criatura y afirmase su relación de dependencia:

«El hombre no puede ejercer su dominio sobre la tierra como si sólo él existiera en el universo o como si él fuera el único ser valioso de toda la creación. Esta función característica ha de cumplirse como una administración confiada por el Creador a quien pertenece la tierra con todas sus criaturas. Durante mucho tiempo, los cristianos han venido pensando en la creación como algo relacionado con el comienzo de las cosas en vez de entenderla como una acción continuada de Dios y una responsabilidad permanente del hombre. Esta visión de las relaciones existente entre Dios, el hombre y la naturaleza pone en tela de juicio todas las actitudes y comportamientos sociales que se desprenden de una postura estrecha y egoísta ante la naturaleza y las relaciones humanas» ${ }^{43}$.

En segundo lugar, se manifestaba la convicción de que existía una estrecha conexión entre la justicia humana y la renovación de la tierra, así como entre la injusticia y el deterioro del medio ambiente. «El reto de la justicia social internacional —-sostenía uno de los informes- nos sale al encuentro en los primeros pasos de toda investigación sobre los problemas del medio ambiente. Ambas crisis están inextricablemente unidas $»^{44}$. Ecología y justicia tenían, por tanto, que abordarse conjuntamente. Los problemas de la tecnología no debían separarse de la lucha a favor de la justicia social.

Ante la constatación de que se habían adoptado prácticas ecológicamente destructivas en interés de una ganancia a corto plazo, ahora se condenaba la idea de una expansión sin límites. Las naciones ricas debían dejar de soñar con elevar indefinidamente sus niveles de vida y comenzar a trabajar por construir un nivel razonable de vida ${ }^{45}$.

«Las sociedades, olvidadas de su responsabilidad para con los demás hombres y para con las futuras generaciones, han medido el éxito en términos de un consumo elevado y de un crecimiento del producto nacional bruto. Hoy, sin embargo, resulta cada vez más evidente la peligrosa inadecuación de tales criterios» ${ }^{46}$.

43 Citado en: ibid., 209.

${ }^{44}$ Gill, Tecnología, fe y futuro del hombre, 13.

${ }_{45}$ Cf. Ibid., 40-42.

46 Citado en: Matabosch, 211. 
Esa exigencia de una utilización responsable de los recursos naturales y la llamada a un consumo responsable, había cristalizado en la Conferencia de Bucarest (1974) en la adopción del concepto de «sostenibilidad». El futuro requería una idea de desarrollo que fuera sostenible a largo plazo, tanto medioambiental como económicamente. El límite de los recursos renovables implicaba un desafío radical a la fe en el progreso. Algunos de los informes apuntaban ya a la posible necesidad de un «desdesarrollo» por parte de las naciones ricas, que tendrían que descender a un nivel más bajo de consumo de recursos. Y alertaban de que ese reajuste podría exigir una revolución económica:

«Las comunidades que durante decenios (por no decir siglos) han estado buscando la elevación constante de nivel de vida, deben buscar ahora una nueva orientación, comenzando a preguntarse qué es lo que constituye un "razonable" nivel de vida para todos los hombres [...] En occidente, los valores y metas heredados se fueron formando como respuesta a la grave escasez de bienes materiales esenciales [...] ahora que se ha superado el problema de la escasez, los occidentales pueden dejar a un lado su preocupación y tratar de fijarse una nueva serie de metas ${ }^{\star 4}$.

Entre esas metas debía contemplarse el compromiso a favor de la justicia económica global, que incluyese una transferencia de tecnología y de sus beneficios a los países en vías de desarrollo, con el objetivo de superar la brecha tecnológica. La tensión entre la llamada a un desarrollo sostenible y la demanda de los países más pobres al desarrollo y a la justicia económica se experimentaba cada vez con más crudeza:

«Cuando esos países intentan acercarse al índice de industrialización y productividad de los Estados Unidos, entonces suscitan en medida creciente los riesgos del desajuste [...] No podemos desde Occidente hacer esta piadosa exigencia al mundo o al Tercer Mundo, si nosotros mismos no estamos dispuestos al sacrificio ${ }^{48}$.

En tercer lugar, se experimentaba con claridad la necesidad de desarrollar una ética ecológica que orientase el crecimiento hacia metas socialmente deseables y promoviese nuevos estilos de vida y acción, tal como había expresado el biólogo australiano Charles Birch:

${ }^{47}$ Gill, Tecnología, fe y futuro del hombre, 81.

48 Ibid., 40. 
«Necesitamos de una ética ecológica, una actitud hacia la naturaleza que sobrepase el mero concepto de utilidad. De lo contrario, la conservación será causa perdida. Aquí la Iglesia puede hacer algo tremendamente significativo, si es que es capaz de decir algo que rompa el hielo» ${ }^{49}$.

Tras varias décadas de desarrollo científico y tecnológico, ahora parecía evidente que se habían introducido procesos técnicos sin una plena comprensión de los resultados que de ellos se podían seguir. Junto a ello, se constataba la tendencia inherente de la tecnología a convertirse en autónoma y servir a sus propios fines. Todo ello implicaba, en muchos casos, repensar las respuestas tradicionales a la luz de las nuevas posibilidades que abría el avance científico. Era preciso articular adecuadamente la tríada libertad-responsabilidad-justicia, porque no todo lo científicamente posible parecía éticamente deseable. La fe cristiana podía ayudar a abordar los dilemas éticos de la era tecnológica. A los teólogos les quedaba encomendaba la tarea de identificar aquellos elementos de la tradición cristiana que pudieran arrojar alguna luz sobre los dilemas de la tecnología y del futuro.

Cada vez calaba con más fuerza la convicción de que las Iglesias debían orientar su pensamiento hacia las exigencias que la ecología suscitaba para la fe y la ética. Parecía claro que el movimiento ecuménico debía ocuparse de los problemas éticos que nacían de las ciencias naturales y de la revolución tecnológica en curso, del mismo modo que en las décadas anteriores se había preocupado de los problemas planteados por las ciencias sociales, tratando de transformar el pensamiento acerca de la responsabilidad cristiana en el mundo moderno. Desde el ámbito científico se esperaba que las Iglesias ofreciesen una nueva ética social que arrojara luz para forjar las directrices adecuadas que permitieran infundir una dirección clara a la tecnología.

Por último, resultaba evidente la necesidad de superar el estéril conflicto entre la ciencia y la religión, dejando atrás siglos de indiferencia y antagonismo entre la fe cristiana y las disciplinas científicas. La Conferencia de Boston (1979) lo expresaba con claridad:

«Se ha iniciado un diálogo prometedor entre la ciencia y la fe, que han dejado de sentirse mutuamente enfrentadas. Por el contrario, hoy se ven obligadas a reflexionar juntas sobre las opciones morales y

${ }^{49}$ Citado en: Vall, 99. 
políticas con que se enfrenta la humanidad a fin de asegurar su propia supervivencia y para superar las crecientes desigualdades que separan a los países ricos de los pobres. De ahí que la ciencia haya dejado de considerarse moralmente neutra, mientras que la fe cristiana descubre de nuevo el valor exhortatorio de la confesión de que el mundo es la creación buena de Dios [...] el diálogo se ha abierto y hemos empezado a reflexionar juntos sobre umbrales éticos, sobre los nuevos problemas morales que tiene planteados hoy la humanidad $»^{50}$.

Con el trasfondo de las conferencias impulsadas por el departamento Iglesia y Sociedad tuvo lugar la V Asamblea del CEI (Nairobi, 1975), de la que se ha escrito que «representa un paso importante en la conciencia ecológica de las Iglesias ${ }^{51}$. Su desarrollo estuvo marcado por la influyente presencia del científico Charles Birch. En su intervención presentó el agónico escenario del mundo como un Titanic avanzando inexorablemente hacia un iceberg del que tan solo se atisbaba a ver algunos de los síntomas más visibles — desertización, contaminación, etc.— de esa gran masa de hielo oculta a la vista que era la crisis ambiental ${ }^{52}$. «Hay algo radicalmente erróneo en nuestro actual modo de vida», afirmaba ante la constatación de que la humanidad se estaba aproximando con rapidez a los límites de crecimiento que nos impone un planeta finito. Revertir la dramática situación en que se encontraba la humanidad — advertíapasa por hacer una transición deliberada hacia una sociedad globalmente sostenible, y ello implicaba una transformación radical de la civilización, de las nuevas tecnologías y los nuevos sistemas económicos y políticos globales. Por ello, interpelaba al auditorio: «¿Estamos dispuestos a pagar el precio de la redención de la tierra en términos de una revolución de valores, de estilos de vida, de metas económicas y políticas e incluso en la naturaleza de la ciencia y la tecnología que practicamos?» ${ }^{53}$. Birch cuestionaba fuertemente el modelo de crecimiento ilimitado. En su lugar proponía el modelo alternativo de una sociedad ecológicamente sostenible y viable, una sociedad que fuera igualmente justa y sostenible, exigencia que cristalizó en su repetida formulación de la sostenibilidad: «los ricos

50 Matabosch, 215-216.

51 Cf. Vall, 102.

52 Charles Birch. "Creation, Technology and Human Survival: Called to Replenish the Earth”. The Ecumenical Review XXVIII, n. ${ }^{\circ} 1$ (1976): 67. DOI: https://doi. org/10.1111/j.1758-6623.1976.tb03201.x

53 Ibid., 67. 
deben vivir más simplemente para que los pobres puedan simplemente vivir» ${ }^{54}$. Su alocución concluía con un llamamiento: «si queremos continuar habitando la tierra, debe producirse una revolución en las relaciones entre los seres humanos. Las Iglesias deben escoger si quieren formar parte de esta revolución ${ }^{55}$.

La interpelación del biólogo australiano recibió respuesta por parte de la asamblea, que hacía un llamamiento a un auténtico ascetismo como medio para caminar hacia la meta de una sociedad justa y globalmente sostenible y establecía como línea directriz para el futuro explorar la contribución de la fe cristiana, la ciencia y la tecnología en la lucha por lograr una sociedad justa y sostenible ${ }^{56}$. Con ello, trataba de conjurar las suspicacias que mostraban los países en vías de desarrollo a que se utilizase la crisis ecológica como un medio para desviar la atención de la injusticia social. Por ello, Nairobi hablará de «una sociedad justa, participatoria y sostenible».

En 1979 tiene lugar la Conferencia mundial de Iglesia y Sociedad en el MIT de Masachusetts, con el tema «La contribución de la fe, la ciencia y la tecnología en la lucha por una sociedad justa, participativa y sostenible» (JPSS). A estas alturas, en el ámbito del CEI había ya dos claras convicciones: que los dos temas sobre los cuales giraría el futuro del mundo eran la justicia y la ecología ${ }^{57}$; y la necesidad de nuevos planteamientos teológicos y éticos que posibiliten una nueva reflexión sobre la naturaleza, la humanidad y Dios.

\section{4. «JUSTICIA, PAZ E INTEGRIDAD DE LA CREACIÓN»: LA CUESTIÓN MEDIOAMBIENTAL EN EL CENTRO DE LA AGENDA ECUMÉNICA}

Sobre las bases que habían asentado las conferencias y asambleas anteriores, la siguiente Asamblea del CEI (Vancouver, 1983), convocaba a las Iglesias a participar en «un proceso conciliar de compromiso mutuo para la justicia, la paz y la integridad de la creación» (JPIC), que quedaba

\footnotetext{
54 Ibid., 70.

55 Ibid., 78.

56 Cf. David M. Paton, ed. Breaking Barriers. Nairobi 1975 (The Official Report of the Fifth Assembly of the World Council of Churches, Nairobi, 23 November-10 December, 1975). London: SPCK, 1976, 303-304.

57 Cf. Vall, 111.
} 
establecido como programa prioritario del CEI para los siguientes años ${ }^{58}$. Las Iglesias de Europa recogían el testigo, respondiendo al llamamiento que el CEI había hecho en Vancouver de iniciar un compromiso mutuo a favor de la justicia, la paz y la integridad de la creación. Bajo el lema «Paz con justicia», y auspiciada conjuntamente por el Consejo de Conferencias Episcopales de Europa (CCEE) y la Conferencia de Iglesias Europeas (KEK), sus presidentes, el cardenal Martini y el metropolita Alexy, convocaban la primera Asamblea Ecuménica Europea, que tendría lugar en la ciudad suiza de Basilea en mayo de 1989. La fecha resultaba especialmente significativa: cuando se cumplía medio siglo del inicio de la Segunda Guerra Mundial y a escasos meses de la caída del muro de Berlín. La asamblea se planteaba con un objetivo bien definido: buscar la aportación de las Iglesias a los grandes desafíos que aquejaban a la humanidad en los ámbitos de la justicia, la paz, la ecología y la defensa de la creación. Se trataba de dar una respuesta conjunta de todos los cristianos a la problemática ético-social del momento presente ya que, como afirmaban los secretarios de la CCEE y la KEK, «la situación lo exige ante el deterioro en que se encuentra la creación y la humanidad. La crisis mundial exige una respuesta cualificada y activa, fundada en la fe cristiana ${ }^{59}$. Conscientes de que, por encima de las fronteras confesionales, los cristianos estaban llamados a hacer el mundo más habitable y la sociedad más fraterna establecían un objetivo: presentar una especie de Carta Magna sobre ética social para los cristianos de Europa y ofertarla a los gobiernos y a la sociedad de nuestro continente ${ }^{60}$. «Nuestro fin primero - afirma el documento final - es dar una respuesta cristiana a los signos de los tiempos. Y por medio de nuestras Iglesias nos dirigimos a los gobiernos y a la sociedad $\aleph^{61}$. Por ello, realizaban un llamamiento a la confesión y la conversión a Dios (metanoia): «Durante demasiado tiempo, hemos permanecido ciegos a las implicaciones y exigencias del Evangelio respecto a la justicia, la paz y la integridad de la creación. Junto con otros, debemos emprender un nuevo comienzo ${ }^{62}$. Y recordaban que la

58 David Gill, ed. Gathered for Life: Official Report VI Assembly WCC. Geneva: WCC,1983, 225.

59 Conferencia de Iglesias Europeas (KEK) - Consejo de las Conferencias Episcopales de Europa (CEE), Paz con Justicia, 11.

60 Cf. Ibid., 19.

61 Ibid., 34.

62 Ibid., 47-48. 
conversión es algo más que la simple aceptación del perdón, que exige cambiar el corazón, las actitudes y las mentalidades:

«Es en el corazón humano, en las actitudes y mentalidades, donde hay que buscar las verdaderas causas de la actual crisis. De ahí surge la falsa ilusión de que el hombre puede modelar el mundo a su antojo, la arrogancia que sobrevalora el papel del ser humano respecto a la vida, la ideología del crecimiento constante sin referencia alguna a valores éticos que están en la base de los sistemas económicos del Oeste y del Este; la convicción de que el mundo ha sido puesto en nuestras manos para que lo explotemos, en vez de para que lo cultivemos y lo cuidemos; la ciega confianza en que los nuevos descubrimientos irán resolviendo los problemas a medida que éstos se vayan planteando, y el subsiguiente menosprecio de los riesgos que acarrea nuestro comportamiento» ${ }^{63}$.

El texto destaca la interdependencia de las dimensiones de la crisis, que ilustra con ejemplos como el problema de los refugiados, o la Amazonía en la que la deforestación está en estrecha relación con la reforma agraria y la injusticia económica. Formula la necesidad de revisar de un modo radical las expectativas que suscitaron la ciencia y la tecnología. En esa línea, proclama la necesidad de instaurar un orden ecológico internacional y reclama que todo desarrollo económico se someta a los criterios de viabilidad medioambiental y de su incidencia en las futuras generacio$n e s^{64}$. Una de las mayores originalidades del documento final está en «la decidida visión teocéntrica y trinitaria que ilumina nuestra responsabilidad respecto a la paz, la justicia y la integridad de la creación ${ }^{65}$. Basilea establece un fundamento trinitario del compromiso cristiano con la creación. En la presentación del documento final, Mon. Infante Florido, vaticinaba que la cuestión medioambiental iría cobrando mayor relieve en los años siguientes:

«Es sabido que de algún tiempo a esta parte se ha empezado a elaborar lo que se llama la "teología de la creación", la cual hunde sus raíces en tantos textos bíblicos, particularmente del Antiguo Testamento; se encuentra perfilada en los escritos de los Santos Padres; fue esbozada en tantas ocasiones por las inspiraciones de los místicos, profundamente

\footnotetext{
63 Ibid., 39.

${ }^{64}$ Cf. Ibid., 62-67.

65 Vall, 136.
} 
compenetrados con la naturaleza; y se ha desarrollado de una manera particular dentro del mundo de la Ortodoxia» ${ }^{66}$.

En el año 2000 tenía lugar la convocatoria mundial de Seúl sobre «Justicia, Paz e Integridad de la Creación ${ }^{67}$. El expresivo título del documento final reflejaba la fuerte conciencia que se tenía de la urgencia del momento. El tiempo apremiaba para resolver las dos grandes cuestiones que concentraron gran parte de la atención: el calentamiento global y el cambio climático. El texto, que en su preámbulo recordaba que Dios había establecido un pacto irrevocable con la creación, recordaba que la integridad de la creación implicaba una dimensión social —paz con justicia-, y una dimensión ecológica.

Un año después se celebró la VII Asamblea del CEI (Canberra, 1991) que, en ámbitos ecuménicos, pasa por ser la asamblea dedicada más específicamente a la cuestión ecológica ${ }^{68}$. A diferencia de otras asambleas, el tema de la creación constituyó el centro de atención. En Canberra, la cuestión medioambiental adquiere plena carta de ciudadanía en el mundo ecuménico. Con un lema formulado a modo de invocación - «Ven Espíritu Santo, renueva la creación»-, la asamblea dedica una de sus cuatro secciones íntegramente a la problemática ecológica. En su análisis, parte de una importante afirmación teológica: la fundamentación trinitaria del misterio infinito del universo y de toda la creación: «Confesamos que el Dios trinitario es fuente de toda vida. El Espíritu Santo [...] testimonia la energía vivificante de Dios presente en todas las cosas y nos recuerda que todas las cosas dependen totalmente de Dios. Por Jesuscristo han sido hechas todas las cosas y, en él, toda la creación llega a su cumplimiento ${ }^{69}$. Los apartados que estructuran la sección señalan los focos principales de atención: I) La teología de la creación, una interpelación para nuestro tiempo; II) Hacia una ética económica y ecológica; III) La Iglesia, llamada a salvaguardar la vida de toda la creación. El informe de

66 Ibid., 11.

${ }^{67}$ Cf. World Council of Churches (JPIC Office). Now is the Time: Final Documents and Other Texts. World Convocation on Justice, Peace and Integrity of Creation, Seoul, Korea 5-12 March. WCC Publications: Geneva, 1990.

68 Conseil oecuménique des Églises. Signes de l'Esprit. Rapport officiel Septième Assemblée, Canberra, Australie, 7 au 20 février 1991. Genève: WCC Publications, 1991.

69 Ibid., 58. 
la sección I comienza describiendo el dramático contexto al que apuntaban ya los principales estudios científicos:

«Nos enfrentamos a un riesgo sin precedentes. Por primera vez en la historia, la acumulación de la actividad humana amenaza con destruir, no solo los escosistemas locales y regionales, sino el conjunto de la ecología planetaria. El calentamiento de la atmósfera terrestre pone gravemente en peligro la supervivencia y el desarrollo del género humano así como de los demás seres vivos ${ }^{70}$.

El documento refleja, además, una firme convicción: que no cabe hacer frente a la ecología sin pasar por la economía. En su análisis, se refiere a dos aspectos interrelacionados de la crisis - una crisis mundial de justicia social y una crisis planetaria ecológica y medioambiental—:

«La búsqueda de la justicia nos impulsa a descubrir nuevas formas de preocuparnos por toda la creación —el sol, el agua, el aire, los seres humanos, la vida vegetal y las demás criaturas vivas-. Esta nueva visión debe integrar todas nuestras necesidades —ecológicas, sociales, económicas, políticas y espirituales-, que son interdependientes. Queremos proclamar, con la mayor fuerza posible, que la justicia social para todos los seres humanos y la "eco-justicia" para toda la creación deben ir de la mano ${ }^{71}$.

La transformación hacia la que apunta deberá ser abordada desde una nueva lógica económica que redefina la relación entre el precio y el valor de las cosas y que no confunda desarrollo con crecimiento. En Canberra se apuesta por una sostenibilidad económica y ecológica.

\section{UNA VISIÓN SACRAMENTAL DEL MUNDO: LA CONTRIBUCIÓN ORTODOXA AL DEBATE MEDIOAMBIENTAL}

El patriarca de Constantinopla Bartolomé I, cuya implicación en la defensa de la creación le ha valido el apodo de "patriarca verde», recordaba no hace mucho la relevante contribución de la Ortodoxia al debate medioambiental en los siguientes términos:

\footnotetext{
70 Ibid., 60 .

71 Ibid., 59.
} 
«La Iglesia de Constantinopla es ampliamente conocida por sus iniciativas ecológicas. Fue la primera en resaltar las dimensiones espiritual y ética del problema ecológico, en acentuar la importancia de la contribución de la Iglesia a su tratamiento, en presentar las dimensiones ecológicas del ethos eucarístico y ascético de la Ortodoxia y en proponer formas de protección del medio ambiente» ${ }^{72}$.

A la presencia de las Iglesias ortodoxas en el seno del CEI se debe la incorporación de una perspectiva trinitaria de la creación o la definición de la Iglesia como una comunidad eucarística en la asamblea de Vancouver (1983). V. Borovoy, representante del patriarcado de Moscú, establecía en aquella asamblea el fundamento eucarístico del compromiso cristiano con el mundo, recordando que la eucaristía es salvación en sus dimensiones humanas y cósmicas ${ }^{73}$. Las diversas consultas que se han realizado en el mundo ortodoxo sobre el tema «Justicia, Paz e Integridad de la Creación» (Sofía, 1987; Patmos, 1988; Minsk, 1989) ${ }^{74}$, la declaración en 1989 por el patriarca Dimitrios del 1 de septiembre como Jornada de Oración por la Creación para toda la Ortodoxia, o las iniciativas impulsadas por el patriarca Bartolomé I, hablan de la especial implicación de la Ortodoxia con la cuestión ambiental. Su perspectiva ha tenido un importante influjo en el mundo ecuménico, introduciendo elementos que pueden contribuir a crear ese ethos ecológico que reclama la supervivencia del planeta. El patriarca Bartolomé I establecía los presupuestos de la visión ortodoxa de la crisis medioambiental que atraviesa el mundo:

«La crisis que afrontamos no es meramente ecológica [...] Es una crisis relacionada con el modo en que nos concebimos y nos imaginamos el mundo. Antes de abordar eficazmente los problemas de nuestro entorno, debemos cambiar, por consiguiente, nuestra autocomprensión y visión del mundo. Se necesita toda una revolución copernicana de nuestra jerarquía de valores, es decir, un ethos radicalmente nuevo» ${ }^{75}$.

${ }^{72}$ Bartolomé I, 621. Sobre la aportación de Bartolomé I a la ecología, véase: John Chryssvagis. On Earth as in Heaven: Ecological Vision and Initiatives of Ecumenical Patriarch Bartholomew. New York: Fordham University Press, 2012.

${ }_{73}$ Cf. Matabosch, 261-262.

${ }^{74}$ Los informes de dichas consultas pueden consultarse en: Gennadios Limouris. Ortodox Visions of Ecumenism (Statements, Messages and Reports on the Ecumenical Movement, 1902-1992). Geneva: WCC Publications, 1994.

75 Bartolomé I, 624. 
Si desde ámbitos protestantes se ha insistido en la dimensión ética y eclesiológica de la problemática ecológica, la Ortodoxia ha puesto el acento en los aspectos litúrgico, sacramental y ascético. Es quizás en este aspecto donde se cifra la contribución más original de la teología ortodoxa al debate medioambiental. El metropolita J. Zizioulas ha insistido en la necesidad de ampliar la perspectiva y superar una postura reduccionista que circunscriba la cuestión medioambiental a categorías exclusivamente éticas. La suya es una invitación a ensanchar la mirada y no olvidar que la cuestión medioambiental no es únicamente un problema de desafíos éticos: "el problema ecológico, aunque se presente como un problema de la ciencia y mucho más todavía de la ética, de la educación y de la legislación estatal, también es un problema teológico» ${ }^{76}$. Zizioulas considera que hay que desmarcar la cuestión medioambiental del ámbito de la ética para situarla en el campo litúrgico:

«Si buscamos resolver el problema ecológico introduciendo nuevos valores morales o reorganizando la jerarquía de los tradicionales, me temo que no iremos demasiado lejos en la tentativa de lograr una solución [...] es necesaria una nueva cultura donde la dimensión litúrgica ocupe un lugar central, y tal vez determine el principio ético» ${ }^{77}$.

Desde la perspectiva ortodoxa, la crisis ecológica está estrechamente vinculada con la pérdida de sacralidad de la naturaleza. Se trataría, a su juicio, de una pérdida de la que el mundo oriental habría quedado a salvo y que afecta principalmente al mundo occidental en el que, con la Ilustración, se destruyó una visión del mundo «según la cual nosotros vivimos como en una realidad misteriosa y sagrada, más extensa de lo que la mente humana es capaz de captar o contener: una "liturgia cósmica", según la descripción del mundo de Máximo el Confesor» ${ }^{78}$. Superar la actual crisis exige recuperar una visión sacramental de la naturaleza. El camino para redescubrir esa mirada capaz de maravillarse ante la creación pasa por una triple vía: una visión sacramental, icónica, que oriente el modo en que percibimos la creación; una visión litúrgica, que impulse el modo en que celebramos la creación; y una práctica ascética, referida

${ }^{76}$ Ioannis Zizioulas. Lo creado como eucaristía (Aproximación teológica al problema de la ecología). Barcelona: Centro de Pastoral Litúrgica, 29.

77 Ibid., 10-11.

78 Ibid., 10. 
al modo en que respetamos la creación, como correctivo necesario de una sociedad consumista ${ }^{79}$.

\section{EL MUNDO COMO «HOGAR DE VIDA»: HACIA UNA NUEVA VI- SIÓN DEL MOVIMIENTO ECUMÉNICO}

Konrad Raiser ha mostrado la convicción de que el movimiento ecuménico está necesitado de una nueva visión: «uno de los mayores desafíos a los que se enfrenta el movimiento ecuménico se cifra en la necesidad de una comprensión de la oikumene centrada en la vida, que abarque toda la creación divina ${ }^{80}$. Si en la asamblea de Upsala (1968) —explica- el movimiento ecuménico dilató el significado de la oikumene para abarcar, más allá del ámbito de las Iglesias cristianas, a la comunidad humana, la conciencia de la amenaza ecológica nos obliga incluso a trascender la oikumene del mundo habitado para reconocer que la oikumene divida abraza a toda la creación de Dios. Propone la expresión «hogar de vida» (household of life) como metáfora de un nueva visión ecuménica que exprese la interrelación de toda vida y ayude a desplegar la noción koinonia en sus dimensiones vertical y horizontal:

«La conciencia ecológica nos obliga a trascender incluso la oikumene del mundo habitado. La oikumene de Dios abraza toda la creación de Dios modelada como una casa (oikos) para ser habitada por todos los seres humanos, que también debe ser protegida y preservada como habitable para las generaciones futuras. La visión de la oikumene debe superar su carácter antropocéntrico e incluir igualmente una visión temporal. Una teología de la creación desarrollada con conciencia ecológica ha comenzado a redescubrir el carácter interdependiente y relacional de toda vida que es sostenida por el poder dador de vida del Espíritu divino. El shalom del sabbath divino está siendo redescubierto como la corona de la creación. Esa fue la intención que llevó a la Asamblea de Vancouver a adoptar la frase "integridad (shalom) de la creación" y no

${ }^{79}$ Cf. John Chryssavgis. "A New Heaven and a New Earth: Orthodox Christian Insights from Theology, Spirituality, and the Sacraments". En Toward an Ecology of Transfiguration (Orthodox Christian Perspectives on Environment, Nature and Creation, editado por John Chryssavgis y Bruce V. Foltz., 152-162. New York: Fordham University Press, 2012.

${ }^{80}$ Konrad Raiser. To be the Church (Challenges and Hopes for the New Millennium). WCC Publications: Geneva, 1997, 19. 
sorprende, por tanto, que el precepto bíblico del sabbath, incluyendo el año sabático y el año de liberación del jubileo, hayan sido redescubiertos como un poderoso símbolo ecuménico. Sobre estos presupuestos he propuesto interpretar el término oikumene con un "hogar de vida" y comenzar explicando las normas de una vida juntos en shalom como miembros de ese "hogar de vida" en el que Dios mediante el Espíritu mora en su creación (Ef 2,19-22)» ${ }^{81}$.

Tras ser elegido secretario general en la Asamblea de Canberra (1991), Raiser manifestaba esperanzado: «Por primera vez en la historia, la unidad de la humanidad, meta última del movimiento ecuménico, parece una realidad tangible». Sin embargo, constatando la situación mundial, concluía con desánimo: «Se diría que la humanidad no está suficientemente madura para gestionar la unidad que se le ha venido encima» ${ }^{82}$. Por ello consideraba imprescindible desarrollar una nueva ética, centrada en la vida, una ética de la sostenibilidad que vaya más allá de una conservación meramente utilitarista y nos recuerde que la tierra entera pertenece a Dios:

«La idea de que la sostenibilidad nos exige practicar una ética de la autolimitación, una nueva forma de ascetismo, que late tras los esfuerzos ecuménicos desarrollados en el ámbito de la Justicia, la Paz y la Integridad de la Creación, ayuda a formular criterios que aseguren la compatibilidad entre nuestros modos de vida y acción y la necesidad de mantener el equilibrio ecológico y los ciclos de la vida de la naturaleza, a respetar los derechos de los pobres y de los refugiados, y salvaguardar los fundamentos de la vida para las generaciones futuras $[\ldots]$ » ${ }^{83}$.

Insiste en la idea, planteada ya en la convocatoria de Seúl, de promover aquellas instituciones que nos puedan ayudar a restaurar una relación adecuada con la creación y a restituir unas relaciones de justicia. Por ello propone recuperar la idea de un jubileo ético y recuperar la estructura sabática de la creación, del sabbath como día de descanso, que ayuden a fraguar una cultura que nos permita vivir en armonía con la creación y posibilite a la naturaleza el descanso y su recuperación.

${ }^{81}$ Konrad Raiser. "Ecumenism in Search of a New Vision". En The Ecumenical Movement. An Anthology of Key Text and Voices, editado por Michael Kinnamon y Brian E. Cope, 76. Geneva: WCC Publications, 1997.

82 Ibid., 72.

83 Konrad Raiser, To be the Church, 54-55. 
Las reflexiones de K. Raiser, junto con los trabajos de Larry Rasmusen o Martin Robra en el campo de la ética, se sitúan en el marco del nuevo programa aprobado por el Comité Central del CEI en 1994, denominado «Teología de Vida: Justicia, Paz, Creación». El programa se orientaba a desarrollar aquellas áreas en las que en Seúl se había constatado una necesidad de ulterior profundización: la ética social, la relación entre eclesiología y ética y la teología de la creación ${ }^{84}$. La reflexión en esos ámbitos ha proseguido, bajo la convicción, expresada por J. Zizioulas, de que las Iglesias y la teología «deben poder decir una palabra significativa sobre una materia como esta o, de otra forma, se arriesgan a ser irrelevantes e incapaces de mantener su pretensión de verdad; porque una verdad que no ofrece la vida está vaciada totalmente de significado» ${ }^{85}$.

\section{A MODO DE CONCLUSIÓN: CUIDAR LA «CASA COMÚN», TAREA PRIORITARIA PARA LA «OIKUMENE» DEL SIGLO XXI}

El recorrido realizado muestra una creciente preocupación del mundo ecuménico por la problemática medioambiental. Las diversas asambleas del CEI, así como las conferencias y documentos de diversos organismos ecuménicos, permiten rastrear una trayectoria que, arrancando de la inicial preocupación por los desafíos que plantea el mundo tecnológico, pasando por la defensa de la sostenibilidad o la defensa de la necesidad de una ética medioambiental, ha avanzado hasta cristalizar en la tríada «Justicia, Paz e Integridad de la Creación» y convertirse en una cuestión central desde la asamblea de Canberra (1991) del CEI. Las reflexiones más recientes apuntan a la actual crisis ecológica como uno de los elementos nucleares en orden a reconfigurar la visión ecuménica de comienzos del tercer milenio.

Si las asambleas del CEI y otros organismos ecuménicos han visibilizado la preocupación y el compromiso de la comunidad ecuménica por la problemática medioambiental, la promulgación en 2015 de la carta encíclica Laudato si' del papa Francisco ha situado la cuestión medioambiental

${ }^{84}$ Cf. Douglas L. Chial. “The Ecological Crisis (A Survey of the WCC's Recent Responses)". The Ecumenical Review 48, n. ${ }^{\circ} 1$ (1996): 57.

85 Zizioulas, 8. 
en el centro de la agenda eclesial católica ${ }^{86}$. Sin ser una cuestión nueva en el magisterio romano, la encíclica ha otorgado un nuevo impulso a la problemática ecológica en el ámbito católico ${ }^{87}$. Considerada como una auténtica summa ecológica, la Laudato si' aborda la problemática ecológica desde sus dimensiones teológica, científica, cultural, política, económica, espiritual y moral. El documento refleja igualmente algo sobre lo que ha insistido el papa Francisco: que los problemas que vive hoy la humanidad reclaman una respuesta ecuménica conjunta por parte de las Iglesias y un diálogo abierto y sincero con las demás religiones. «No podemos ignorar - afirma el texto- que, también fuera de la Iglesia Católica, otras Iglesias y Comunidades cristianas —como también otras religiones - han desarrollado una amplia preocupación y una valiosa reflexión sobre estos temas que nos preocupan a todos» (n. 7). Por ello, la perspectiva ecuménica no ha faltado en el documento. El papa Francisco se refiere explícitamente a la destacable contribución del patriarca Batolomé I (nn. 8 y 9$)^{88}$.

${ }^{86}$ De la amplia bibliografía publicada sobre la encíclica, puede consultarse: Enrique Sanz Giménez-Rico, ed. Cuidar de la tierra, cuidar de los pobres (Laudato si' desde la teología y con la ciencia). Santander: Sal Terrae, 2015; Idelfonso Camacho Laraña. "Laudato si": el clamor de la tierra y el clamor de los pobres. Una encíclica más que ecológica”. Revista de Fomento Social 71 (2016): 59-79; Tomás Trigo, ed. Cuidar de la creación. Estudios sobre la encíclica Laudato si'. Pamplona: EUNSA, 2016; Susana Aulestiarte y Reyes Duro, eds. Ecología y desarrollo humano. Conversaciones sobre "Laudato sí". Pamplona: Ediciones Universidad de Navarra, 2017; Federico Lombardi y Fernando F. Sánchez Campos. Laudati si'. El cuidado de la casa común, una conversión necesaria a la ecología humana. Madrid: BAC, 2018; Rafael Amo Usanos. "Fundamentos de ecología integral". Estudios Eclesiásticos 94 (368): 5-37. DOI: https://doi.org/10.14422/ee.v94.i368.y2019.001

${ }^{87}$ Sobre la cuestión ecológica en el magisterio católico, puede consultarse: Jaime Tatay. Ecología integral (La recepción católica del reto de la sostenibilidad). Madrid: BAC, 2018; Pablo Blanco. "In the beginning' (Gn 1:1, Jn 1:1). creation, nature and ecology according with Joseph Ratzinger - Benedict XVI". En "Ins Herz geschrieben". Die grundlagen des freiheitlichen Rechtsstaates. Aufsätze und Diskussionsbeiträge aus Anlass der Internationalen Tagung am 10. Juni 2013 an der Katholischen Universität Pázmány Péter in Budapest, editado por Nadja El Beheiri y János Erdögy, 95-115. Budapest: Pázmány Press, 2014.

${ }_{88}$ Iniciativas como su decisión de unirse al patriarcado ecuménico en la celebración del día 1 de septiembre como "Día para la protección del medio ambiente», o los mensajes conjuntos emitidos con el patriarca Bartolomé I con ocasión de la Jornada Mundial de Oración por la Creación, apuntan a la sintonía del papa Francisco con la reflexión y el compromiso de la Ortodoxia en la cuestión medioambiental, 
Su propuesta de una ecología integral, como respuesta a la actual crisis socioambiental, se suma como una importante contribución a la reflexión que desde otras Iglesias y comunidades eclesiales, así como desde organismos ecuménicos, se ha venido realizando en las últimas décadas. En sintonía con la reflexión desarrollada en ámbitos ecuménicos, el documento señala la estrecha relación que media entre ecología y justicia, apunta a la teología de la creación como una de las aportaciones más significativas que se puede realizar desde la fe cristiana, destaca las dimensiones ética y espiritual de la cuestión medioambiental, al tiempo que apunta a la antropología como una de las dimensiones más nucleares ${ }^{89}$.

$\mathrm{El}$ "cuidado de la casa común» se ha convertido en una prioridad de la agenda ecuménica, desde la convicción, expresada por el secretario del CEI en vísperas de la reciente Cumbre sobre el Clima de Naciones Unidas celebrada en Nueva York, de que en nuestro tiempo «no podemos ignorar o destruir la creación de Dios y seguir proclamando que amamos a Dios y aquello que Dios ha creado» ${ }^{90}$.

\section{REFERENCIAS}

Amo Usanos, Rafael. "Fundamentos de ecología integral”. Estudios Eclesiásticos 94, n. ${ }^{\circ} 368$ (2019): 5-37. DOI: https://doi.org/10.14422/ee.v94. i368.y2019.001

Aulestiarte, Susana, y Reyes Duro, eds. Ecología y desarrollo humano. Conversaciones sobre "Laudato sí". Pamplona: Ediciones Universidad de Navarra, 2017.

Bartolomé I. "Eclesiología como ecología". Concilium 378 (2018): 621-630. Blanco, Pablo. "In the beginning' (Gn 1:1, Jn 1:1). creation, nature and ecology according with Joseph Ratzinger - Benedict XVI". En "Ins Herz, geschrieben". Die grundlagen des freiheitlichen Rechtsstaates. Aufsätze und Diskussionsbeiträge aus Anlass der Internationalen Tagung am 10. Juni 2013 an der Katholischen Universität Pázmány Péter in Budapest,

especialmente en la tarea de configurar un ethos medioambiental con su representante más emblemático, el patriarca Bartolomé I.

89 «No hay ecología sin una adecuada antropología» (LS 118).

90 Olav Fykse. "Sermón en el Marble Collegiate Church, Nueva York, 22 septiembre 2018". Consultado el 1 de octubre de 2019. https://www.oikoumene.org/es/ press-centre/news/index-es/do-you-love-me-its-a-question-about-global-warming 
editado por Nadja El Beheiri y János Erdögy, 95-115. Budapest: Pázmány Press, 2014.

Birch, Charles. "Creation, Technology and Human Survival: Called to Replenish the Earth". The Ecumenical Review XXVIII, n. ${ }^{\circ} 1$ (1976): 66-79. DOI: https://doi.org/10.1111/j.1758-6623.1976.tb03201.x

Camacho Laraña, Ildefonso. "Laudato si': el clamor de la tierra y el clamor de los pobres. Una encíclica más que ecológica”. Revista de Fomento Social 71 (2016): 59-79. DOI: https://doi.org/10.32418/rfs.2016.281.1359

Comité Español de Cooperación entre las Iglesias - Centro Ecuménico Misioneras de la Unidad, eds. Paz con Justicia. Documentación oficial de la Asamblea Ecuménica Europea. Basilea, 15-21 mayo 1989. Madrid: 1990.

Conferencia de Iglesias Europeas (KEK) - Consejo de las Conferencias Episcopales de Europa (CEE). Paz con Justicia. Documentación oficial de la Asamblea Ecuménica Europea. Basilea, 15-21 mayo 1989. Madrid: Centro Ecuménico Misioneras de la Unidad, 1990.

Conferencia de Iglesias Europeas (KEK) - Consejo de Conferencias Episcopales de Europa. Reconciliación: don de Dios y fuente de vida nueva (Segunda Asamblea Ecuménica Europea, Graz 1997). Madrid: PPC, 1997.

Conseil oecuménique des Églises. Signes de l'Esprit. Rapport officiel Septième Assemblée, Canberra, Australie, 7 au 20 février 1991. Genève: WCC Publications, 1991.

Consejo Ecuménico de Iglesias. Upsala 1968. Informes, declaraciones y alocuciones. Salamanca: Sígueme, 1969.

Chial, Douglas L. "The Ecological Crisis (A Survey of the WCC's Recent Responses)". The Ecumenical Review 48, n. ${ }^{\circ} 1$ (1996): 53-61.

DOI: https://doi.org/10.1111/j.1758-6623.1996.tb02941.x

Chryssavgis, John. On Earth as in Heaven: Ecological Vision and Initiatives of Ecumenical Patriarch Bartholomew. New York: Fordham University Press 2012.

Chryssavgis, John. "A New Heaven and a New Earth: Orthodox Christian Insights from Theology, Spirituality, and the Sacraments". En Toward an Ecolgy of Transfiguration (Orthodox Christian Perspectives on Environement, Natura and Creation, editado por John Chryssavgis y Bruce V. Foltz, 152-162. New York: Fordham University Press, 2012.

Chryssavgis, John. Creation as sacrament. London: T \& T Clark, 2019.

Departamento Iglesia y Sociedad. Los cristianos en las revoluciones técnicas y sociales de nuestro tiempo. Documentos de la conferencia mundial 
sobre Iglesia y Sociedad (Ginebra, 12-26 julio 1966). Santander: Sal Terrae, 1971.

Faith and Order Commission. "God in nature and History". En New Directions in Faith and Order, Bristol 1967. Reports, Minutes, Documents, 7-32. Geneva: World Council of Churches, 1968.

Fykse, Olav. "Sermón en el Marble Collegiate Church, Nueva York, 22 septiembre 2018". Consultado el 1 de octubre de 2019. https://www.oikoumene.org/es/press-centre/news/index-es/ do-you-love-me-its-a-question-about-global-warming

Francisco. Carta encíclica Laudato si' sobre el cuidado de la casa común. AAS 107 (2015): 847-945.

Gibellini, Rosino. "El debate teológico sobre ecología". Concilium 261 (1995): 901-912.

Gill, David M., ed. Tecnología, fe y futuro del hombre. Salamanca: Sígueme, 1972.

Gill, David M., ed. Gathered for Life: Official Report VI Assembly WCC. Geneva: WCC Publications, 1983.

Granberg-Michaelson, Wesley. "Creation in Ecumenical Theology". En Ecotheology, Voices from South and North, editado por David G. Hallman, 96-106. Geneva: World Council of Churches, 1994.

Javierre, José María. "Upsala 1968: el diálogo ecuménico bajo el signo de la antropología". Revista Española de Teología 28 (1968): 255-296.

Lombardi, Federico, y Fernando F. Sánchez Campos. Laudato si'. El cuidado de la casa común, una conversión necesaria a la ecología humana. Madrid: BAC, 2018.

Limouris, Gennadios. Ortodox Visions of Ecumenism (Statements, Messages and Reports on the Ecumenical Movement, 1902-1992). Geneva: WCC Publications, 1994.

Matabosch, Antonio. Liberación humana y unión de las Iglesias. El Consejo Ecuménico entre Upsala y Nairobi (1968-1975). Ediciones Cristiandad: Madrid, 1975.

Moltmann, Jürgen. Dios en la creación. Salamanca: Sígueme,1987.

Oldham, John H., ed. The Oxford Conference (Official Report). Chicago: 1937.

Paton, David M., ed. Breaking Barriers. Nairobi 1975 ((The Official Report of the Fifth Assembly of the World Council of Churches, Nairobi, 23 November-10 December, 1975. London: SPCK, 1976. 
Raiser, Konrad. To be the Church (Challenges and Hopes for the New Millennium). Geneva: WCC Publications, 1997.

Raiser, Konrad. "Ecumenism in Search of a New Vision". En The Ecumencal Movemet. An Anthology of Key Text and Voices, editado por Michael Kinnamon and Brian E. Cope, 70-77. Geneva: WCC Publications, 1997.

Sanz Giménez-Rico, Enrique, ed. Cuidar de la tierra, cuidar de los pobres (Laudato si' desde la teología y con la ciencia). Santander: Sal Terrae, 2015.

Sittler, Joseph A. "Called to Unity”. The Ecumenical Review XIV, n. 2 (1962): 177-187. DOI: https://doi.org/10.1111/j.1758-6623.1962.tb01999.x

Tatay, Jaime. Ecología integral (La recepción católica del reto de la sostenibilidad). Madrid: BAC, 2018.

Trigo, Tomás, ed. Cuidar de la creación. Estudios sobre la encíclica Laudato si'. Pamplona: EUNSA, 2016.

Vall, Héctor. A la búsqueda de una nueva sociedad (Dimensión social del ecumenismo). Madrid: Sociedad de Educación Atenas - Centro Ecuménico «Misioneras de la Unidad», 1997.

Uehlinger, Christoph. "El clamor de la tierra, el clamor de los pobre. Perspectivas bíblicas sobre el tema "ecología y violencia". Concilium 261 (1995): 797-816.

Vischer, Lukas. "The Theme of Humanity and Creation in the Ecumenical Movement". En Sustainable Growth - A Contradiction in Terms? Economy, Ecology and Ethics After the Earth Summit, Report of the Visser't Hooft Memorial Consultation, The Ecumenical Institute, Château de Bossey, June 14-19, 1993, 69-88. Geneva: World Council of Churches, 1993.

White, Lynn. "The Historical Rootes of Our Ecological Crisis". Science 155, n. ${ }^{\circ} 3767$ (1967): 1203-1207. DOI: https://doi.org/10.1126/ science.155.3767.1203

World Council of Churches (JPIC Office). Now is the Time: Final Documents and Other Texts. World Convocation on Justice, Peace and Integrity of Creation, Seoul, Korea 5-12 March. WCC Publications: Geneva, 1990. Zizioulas, Ioannis. Lo creado como eucaristía (Aproximación teológica al problema de la ecología). Barcelona: Centre de Pastoral Litúrgica, 2015. 